\title{
Epidemiology, the Main Reasons and Maternal-Fetal Complications of Unassisted Childbirth in the Health District of V Bamako Commune, Mali
}

\author{
Soumana Oumar Traoré1, Cheickna Sylla², Saleck Doumbia1, Alou Samaké3, Amadou Bocoum ${ }^{4}$, \\ Seydou Fané4, Rokiatou Torian Sangaré1, Fatoumata Keita1, Ibrahima Tegueté4, \\ Youssouf Traoré4, Niani Mounkoro4, Mamadou Traoré1, Amadou Ingré Dolo4 \\ ${ }^{1}$ Obstetric Gynecology Department, The Reference Health Centre of Commune V, Bamako, Mali \\ ${ }^{2}$ Obstetric Gynecology Department, The Koutiala Reference Health Centre, Koutiala, Mali \\ ${ }^{3}$ Obstetric Gynecology Department, The Commune VI Reference Health Centre, Bamako, Mali \\ ${ }^{4}$ Obstetric Gynecology Department, The Gabriel Touré University Hospital Centre, Bamako, Mali \\ Email: Traoreoumar69@yahoo.fr, scheichylla@yahoo.fr, drsaleck@yahoo.com, abocoum2000@yahoo.fr, seydoufane@yahoo.fr, \\ s.rokiatou@spmsarl.org, lafatitike@Gmail.Com, mamadoutre1981@yahoo.fr, teguetibra@hotmail.com,dryoussouf@yahoo.fr, \\ aichaniani@yahoo.fr,mtraore54@yahoo.fr, adolo@afribonemali.ml
}

How to cite this paper: Traoré, S.O., Sylla, C., Doumbia, S., Samaké, A., Bocoum, A., Fané, S., Sangaré, R.T., Keita, F., Tegueté, I., Traoré, Y., Mounkoro, N., Traoré, M. and Dolo, A.I. (2020) Epidemiology, the Main Reasons and Maternal-Fetal Complications of Unassisted Childbirth in the Health District of V Bamako Commune, Mali. Open Journal of Obstetrics and Gynecology, 10, 1381-1395. https://doi.org/10.4236/ojog.2020.10100127

Received: August 29, 2020

Accepted: October 11, 2020

Published: October 14, 2020

Copyright $\odot 2020$ by author(s) and Scientific Research Publishing Inc. This work is licensed under the Creative Commons Attribution International License (CC BY 4.0).

http://creativecommons.org/licenses/by/4.0/ (c) (i) Open Access

\begin{abstract}
Objective: To describe the epidemiological aspects, to determine the reasons leading women to give birth outside of health facilities and to determine the maternal prognosis. Patients and Methods: This was a cross-sectional, analytical, quantitative and qualitative descriptive study over a period from 1 June to 31 December 2016 (7 months) on unassisted childbirth in the health district of commune V of Bamako. Results: We recorded 70 unsured deliveries, a frequency of $1.04 \%$ out of a total of 6719 deliveries. The extreme ages were 15 years and 41 years with an average age of 28 years. $90 \%$ of the birth attendants were married and 10\% were single. The women's profession: $48 \%$ were housewives, $11 \%$ saleswomen, $13 \%$ hairdressers, $4 \%$ female teachers. Education level: $71 \%$ were uneducated and $29 \%$ educated. Among those who are educated, their level was primary in 50\%, secondary in $32 \%$ and higher in $18 \% .42 \%$ had done antenatal consultation. The main reasons: ignorance of work 44.3\%; religious beliefs and societal burdens $10.0 \%$; fear of caesarean section 4.3\%; late-night birth labour 5.7\%; lack of financial and/or transport means $17.1 \%$; distance from the locality $2.9 \%$; insecurity $2.9 \%$. Maternal and perinatal prognosis: complications were mostly hemorrhagic and concerned 27 (39\%) patients. These included uterine atony (13 cases), placental retention (8 cases), soft part lesions ( 6 cases). We have not recorded any maternal
\end{abstract}


deaths. For the condition of newborns at the time of admission: $88 \%$ of newborns were alive, $11 \%$ were stillborn fresh and $1 \%$ stillborn macerated. Conclusion: The reasons are multifactorial and seem to be a reflection of our society.

\section{Keywords}

Childbirth, Unsured, Reasons

\section{Introduction}

Home births without medical assistance continue to be a concern for all development actors in developing countries [1]. In industrialized countries, almost all births are attended by qualified health workers [2]. In these countries, maternal mortality is very low, while in developing countries, more than 300 million women currently suffer from chronic conditions, as a result of pregnancy and childbirth [3]. In Mali, according to the Demographic and Health Survey VI of 2018 (EDSM 2018) VI, the ratio of maternal mortality is estimated at $373 \mathrm{ma}$ ternal deaths per 100,000 live births [4]. Mali, like the countries of the sub-region, in recent years has seen the result of numerous maternity units and the recruitment of qualified staff aimed at reducing maternal, perinatal and child morbidity and mortality. At the same time, regular monitoring of pregnancies and the promotion of hospital delivery, family planning have played a major role in reproductive health activities. However, despite these efforts, some women continue to give birth without medical assistance [5]. WHO estimates that more than 20 million women suffer from unsured childbirth-related ailments each year [6]. Many mothers do not have access to modern health care services. It is estimated that between $60 \%$ and $80 \%$ of women in developing countries continue to give birth at home without any assistance or with the help of unskilled and usually unsafe people. In Mali, in 2012-13, 43\% of deliveries took place in the home [7]. Ignorance and poverty have been cited as reasons for home births [8]. Beyond the figures, we initiated this work with the aim of determining the reasons leading women to give birth outside health facilities without the help of qualified staff in commune $\mathrm{V}$ of Bamako district.

Objective: the aim was to write down the epidemiological aspects, to determine the reasons leading women to give birth outside health facilities and the maternal prognosis in the health district of commune $\mathrm{V}$ of Bamako, Mali.

\section{Patients and Methods}

We carried out a cross-sectional, descriptive, quantitative and qualitative prospective study in the health district of the commune $\mathrm{V}$ of Bamako (10 health areas) from 1 June to 31 December 2016 (7 months). The study population was represented by all the births recorded in the health district of Commune $\mathrm{V}$. Sample size: we recorded all cases of unsured births during the 7-month study 
period based on our criteria. Inclusion criteria: All women who met the definition of out-of-maternity delivery without qualified staff were included in this study and who presented themselves for some reason in any of the health structures involved in the study ( 10 community health centres, and the commune V reference health centre). Exclusion criteria: patients who did not accept the study. A structured questionnaire was developed and a pre-test was administered in the two structures of the neighbouring commune (commune VI) in order to make possible corrections to this questionnaire. We collected patient accounts of the reasons and circumstances that led to this type of unsecured delivery. The information gathered at the interrogation was supplemented from the birthing, admission, reference/evacuation records, obstetric records, antenatal consultation books. As with any human study, we sought and obtained the informed consent of each patient prior to the questionnaire. Confidentiality and anonymity were also respected. The data was entered on Word 2010 and Excel 2010 and analyzed on the Epi-Info Version 3.5.3 software.

\section{Results}

\subsection{Epidemiological Aspects}

During the study period, we recorded 70 unsured deliveries, a frequency of $1.04 \%$ out of a total of 6719 deliveries. The extreme ages were 15 years and 41 years with an average age of 28 years. Average parity was 4 with extremes of 1 and 8 . The women's profession: $48 \%$ were housewives, $11 \%$ saleswomen, $13 \%$ hairdressers, $4 \%$ female teachers. $77 \%$ of patient procreators were in a non-income-generating profession. $90 \%$ of the birth attendants were married and $10 \%$ were single. Education level: $71 \%$ were uneducated and $29 \%$ educated. Among those who are educated, their level was primary in 50\%, secondary in $32 \%$ and higher in $18 \% .42 \%$ had done antenatal consultation. Epidemiological aspects are summarized in Table 1.

\subsection{The Main Reasons Given for Deliveries outside Health Facilities}

There were many reasons why patients gave birth outside the maternity ward without assistance. For example, we noted:

1) Ignorance of the labour was evoked by $44.3 \%$ of the patients, as Ms. MS, 15, testified, "it was my first pregnancy, when the pain started, it was coming, it was going, but since I didn't know, for a while I had the urge to go to the saddle, so I went back to the toilet and that's where I gave birth".

2) Accessibility difficulties: $17.1 \%$ were patients, resulting in a significant number of unassisted births outside the maternity ward. So to this patient Mrs. KD 28 years to say "I last live the river in commune I, but I did my prenatal follow-up with my sister-in-law who is Sagefemme here in the Mali district. When I started to get hurt I called my husband who was at work, as soon as he arrived we took the road to the maternity ward of Mali, but on the bridge there was traffic jam so it put us late and I ended up giving birth in the car". 
Table 1. Epidemiological aspects.

\begin{tabular}{|c|c|c|c|c|c|c|c|c|}
\hline Age & Staff & $\%$ & Profession & Staff & $\%$ & $\begin{array}{l}\text { Profession of the } \\
\text { procreator }\end{array}$ & Staff & $\%$ \\
\hline $15-19$ Years & 6 & 8.6 & Housewives & 34 & 48 & Renumerator & 16 & 23 \\
\hline 20 - 34 Years & 58 & 82.6 & Vendors & 11 & 16 & Non-Renumerator & 54 & 77 \\
\hline$\geq 35$ & 6 & 8.6 & Hairdressers & 9 & 13 & Marital status & Staff & $\%$ \\
\hline Instruction & Staff & $\%$ & Teachers & 3 & 4 & Married & 63 & 90 \\
\hline Educated & 50 & 71 & Other & 13 & 19 & Single & 7 & 10 \\
\hline Not educated & 20 & 29 & Prenatal consultations & Staff & $\%$ & Pregnancy type & Staff & $\%$ \\
\hline Educational level & Staff & $\%$ & 0 & 10 & 14 & Single-fetal pregnancy & 65 & 93 \\
\hline Primary & 11 & 50 & $1-2$ & 21 & 30 & Twin pregnancy & 5 & 7 \\
\hline Secondary & 7 & 32 & $3-4$ & 29 & 42 & Parity & Staff & $\%$ \\
\hline \multirow[t]{4}{*}{ Higher } & 4 & 18 & $\geq 4$ & 10 & 14 & Primipare & 18 & 25.7 \\
\hline & & & & & & Paucipare & 26 & 37.1 \\
\hline & & & & & & Multipare & 26 & 37.2 \\
\hline & & & & & & Total & 70 & 100.0 \\
\hline
\end{tabular}

3) Religious beliefs and modesty: were evoked in 7 cases or $10.0 \%$. Ms. AY, 28, suggested: "I am a Sunni Muslim, I did my prenatal follow-up here in The Mali Quarter with my Midwife. When I was in pain, I couldn't reach her on the phone and since she had told me before that it was the young male doctors who give birth at night, I preferred to give birth at home. Because my religion forbids a woman from being consulted by a man. It was my husband who forced me to come after the birth."

4) The poor quality of the reception: may have been the cause of unassisted maternity leave in $12.7 \%$ of patients, as Ms. AY attests, “... If I get pregnant again; I will prefer to give birth at home as long as the doctors do not change their behavior (insult, scam, contempt, etc...). As soon as you arrive, you are made to pay for antlys and gloves, after you are given prescriptions every hour to pay... sometimes with themselves."

5) A history of childbirth outside health facilities: $2.9 \%$ of patients had a history of off-maternity delivery without assistance. This is the case of this patient A K 27 years: "There is no point in doing prenatal consultations. Whether you do prenatal follow-up or not the pregnancy will evolve. Besides, I did 5 maternity units (in the village) without going through a doctor. It was here that I was forced to do prenatal follow-up and I gave birth again without assistance and without problems at home."

6) Haunting or Fear of Caesarean section: Two of them, $4.3 \%$, reported having had the haunting or fear of caesarean section. This is the case of Ms. BC who states: "When I gave birth last year, as soon as I arrived, the doctors took me into the operating room without telling me anything. This time when I started to feel bad I went to the community health centre, there I was told to go 
to the Mali district (place of the first caesarean section); I was afraid of having surgery again. I preferred to go to the house where I gave birth; and when my husband arrived, he took me to the hospital to check on my health and that of the child."

7) Insecurity: Two other patients, $2.9 \%$, mentioned insecurity as Ms. SM, 26, attests: "It was very late at night, right now there is insecurity everywhere. I thought I could hold the pain until the morning, when it became unbearable I woke up my husband, who went to look for a means of transport, we know that at this time of night taxis are rare, I gave birth before my husband found a taxi. How I felt hurt so we came to the hospital."

The main reasons for unsured births are summarized in Table 2.

Maternal and perinatal prognosis: Complications were mostly hemorrhagic and concerned 27 (39\%) Patients. These included uterine atony (13 cases), placental retention (8 cases), soft part lesions (6 cases). We have not recorded any maternal deaths. For the condition of newborns at the time of admission: $88 \%$ of newborns were alive, $11 \%$ were stillborn fresh and $1 \%$ stillborn macerated. The maternal-fetal prognosis is summarized in Table 3.

\section{Discussion}

\subsection{Epidemiological Aspects}

During the study period, we recorded 6719 deliveries, 70 of which were non-assisted, representing a frequency of $1.04 \%$. This rate does not reflect reality. This is a hospital rate, not taking into account cases of childbirth in the community (not seen in a health structure). A community survey on the subject could have led to an increase in this rate. In Mali's Demographic and Health Survey VI (2018) [4], it is reported that one in three women (33\%) gave birth at home in the previous 5 years. The same observation was made by many authors in Côte d'Ivoire (44\%) [3], in Niamey, Niger (26\%) St. Louis, Senegal (50\%) [9].

Table 2. The main reasons for unsured births.

\begin{tabular}{ccc}
\hline Reasons for unsurred births & Effective & Percentage \\
\hline Poor reception of health services & 9 & 12.9 \\
Ignorance of childbirth & 31 & 44.3 \\
A history of unsurred delivery & 2 & 2.9 \\
Religious belief and modesty & 7 & 10.0 \\
Haunting or fear of caesarean section & 3 & 4.3 \\
Late birthing work at night & 4 & 5.7 \\
Difficulties related to access/Lack of financial & 12 & 17.1 \\
means and/or transport & & 2.9 \\
Insecurity & 2 & 100.0 \\
\hline
\end{tabular}


Table 3. Maternal and perinatal prognosis.

\begin{tabular}{|c|c|c|c|c|c|c|c|c|}
\hline $\begin{array}{c}\text { Causes of postpartum } \\
\text { haemorrhage }\end{array}$ & Staff & $\%$ & Newborns & Staff & $\%$ & $\begin{array}{l}\text { Reference reasons in } \\
\text { neonatology }\end{array}$ & Staff & $\%$ \\
\hline Uterine atony & 13 & 48.1 & Living & 66 & 88 & Hypotrophy & 11 & 45.8 \\
\hline Placental retention & 8 & 29.6 & Fresh stillbirths & 8 & 11 & Mother HIV positive & 1 & 4.2 \\
\hline Injury of the soft parts & 6 & 22.2 & Macerated stillbirths & 1 & 1 & Prematurity & 9 & 37.5 \\
\hline Total & 27 & 100.0 & Total & 75 & 100.0 & Neonatal asphyxia & 3 & 12.5 \\
\hline Mother & Staff & $\%$ & & & & Total & 24 & 100. \\
\hline Living & 70 & 100 & & & & & & \\
\hline Deceased & 0 & 0 & & & & & & \\
\hline Total & 70 & 100 & & & & & & \\
\hline
\end{tabular}

The average age of the patients was 28 years with extremes of 13 years and 41 years; $77 \%$ of the procreators were in unpaid occupations; $14 \%$ had not done any antenatal consultations; 71\% were uneducated. Lankoandé J [10] in Burkina Faso found that 81.60 per cent of women who give birth at home were out of school. Blessed J in Côte d'Ivoire quoted by VrohBi found that half of the women who gave birth at home had no level of education. These same characteristics have been reported by Kouakou A et al. [11].

In our study, 26 (37.1\%) patients were multiparous with an average parity of 4 (with extremes of 1 and 8). In Guinea, Diallo FB et al. [12] found that $48.67 \%$ of women who gave birth at home were large multiparous.

\subsection{The Main Reasons Cited by Women}

The reasons for non-assisted motherhood are multifactorial, varying from continent to continent, country to country and study to study with some consistency. Thus, in this study, we noted: ignorance of the labour of childbirth: it was evoked by $44.3 \%$ patients. The problem of accessibility, be it geographical, financial has led to unassisted maternity births in $17.1 \%$. In Mali's Demographic and Health Survey VI (2018) [4], it is reported that distance, inaccessibility, and lack of adequate infrastructure have led one in three women to give birth at home without assistance (33\%). Diallo et al. [12] in Guinea (Conakry) showed that the remoteness of the health structure was the reason for home birth for 58.41 per cent of women. In an Ivorian study [3], the cost of care was reported by women. In this study, more than half of the women who gave their opinion on the issue, found the cost of childbirth too high, not to mention the racketeering that contributed greatly: affordability is therefore a factor that can help the decision to give birth at home according to these authors. Religious beliefs and modesty were mentioned in 7 patients or $10.0 \%$. Poor quality of care may have been the cause of non-assisted maternity delivery in $12.7 \%$ of patients. Ivorian authors [3] have found that there is twice as much risk of having a birth at home when the reception is not of quality at the maternity ward. The poor quality of 
reception perceived by women is often due to long queues in Ivorian health facilities. This is due not only to the lack of health personnel, but also to the delay in hours of health care. In the same study, the authors reveal that the quality of care revealed that one-third of women who found care to be poor, gave birth at home. Statistical analysis showed that there was a three-times increased risk of giving birth at home when the woman was convinced that she would not be cared for in the maternity ward. The cost of care has been reported by women; more than half of the women who gave their opinion on the issue found the cost of childbirth too high, not to mention the racketeering that contributed greatly to it: affordability is therefore a factor that can help the decision to give birth at home [3].

A previous successful home birth, often experienced by women as an act of bravery, can be a factor in the recurrence of this often perilous experience for the mother-child couple. Thus, in our series $2.9 \%$ patients had a history of home birth. In other qualitative studies on home birth, authors report that [13] "10 percent of women talk about a well-lived home birth" and that others say "giving life at home is a positive event, giving a sense of power, and very satisfying".

The haunting or fear of caesarean section may be grounds for women to be detained in the community where they give birth. Also, in our study, $4.3 \%$ of patients reported having had the haunting or fear of being caesareanized again. According to the National Birthday Trust Fund [13], 11\% of women who have given birth at home cite as the reason for this choice, "a hospital birth poorly lived" and $10 \%$, "the fear of the hospital, the rejection of protocols and regulations". Some authors [3] report that the main reasons cited by these women were the misuse of certain medical practices such as episiotomy, the lack of psychological assistance thus increasing the stress associated with childbirth or the untimely prescribing of caesarean sections showing the incompetence of midwives to perform a vaginal delivery.

The insecurity of recent years may have been a barrier to access to maternity services for some women. Thus $2.9 \%$ patients in our series blamed insecurity. According to the National Birthday Trust Fund [13], for women, the choice of place of delivery is based on different reasons: $30 \%$ evoke intimacy, respect; $25 \%$ mention the practicality, convenient, the presence of the family; $24 \%$ talk about reduced stress, better control and involvement; $11 \%$ mention a hospital birth that is poorly lived; $4 \%$ mention overall support and continuity of care.

In other qualitative studies on home birth, women say that giving life at home is a positive event, giving a sense of power, and very satisfying.

\section{Maternal and Perinatal Prognosis}

Complications were mainly hemorrhagic and affected 27 (39\%) patients. These included uterine atony (13 cases), placental retention (8 cases), soft part lesions (6 cases). This result contrasts with the literature. For almost all studies agree that women who give birth at home have significantly fewer perineal tears than 
the same women who give birth in hospital. Olsen's meta-analysis, including six studies, found ORs less than 1 consistently in favour of home [14]. Hemorrhages are less common at home and statistically significant in half of the studies [15]. However, it should be noted that all of these meta-analyses focused on home births planned and assisted by qualified medical personnel (Wise Women or Physicians) in highly medicalized countries. Maternal mortality in our study was zero like many other studies [16] [17] [18] [19] [20].

For the condition of newborns at the time of admission: $88 \%$ of newborns were alive, $11 \%$ were stillborn fresh and $1 \%$ stillborn macerated.

\section{Conclusion}

Unassisted home delivery is common in Bamako Commune V. The reasons are multifactorial and seem to be a reflection of our society.

\section{Conflicts of Interest}

The authors declare no conflicts of interest regarding the publication of this paper.

\section{References}

[1] Kaimba, C. (1997) The Situation of Home Births in the Commune of Adjamé. Mesm. CES of Obstetrics and Gynecology. Cocody University, Abidjan, 113.

[2] WHO (2005) World Health Report. Geneva, 12.13RCI.

[3] Bi, V., Issaka, T., Pétronille, Z.-A., Judith, G.D., Simplice, D., Janine, T.-S. and Joseph, B. (2009) Prevalence and Determinants of Home Births in Two Precarious Neighbourhoods of Yopougon Commune (Abidjan), Côte d'Ivoire. Public Health, 21, 499-506. https://doi.org/10.3917/spub.095.0499

[4] National Institute of Statistics (INSTAT), Planning and Statistics Unit Health and Social Development and Family Promotion (CPS/SS-DS-PF) and ICF (2019) Demographic and Health Survey in Mali 2018. INSTAT, CPS/SS-DS-PF and ICF, Bamako and Rockville.

[5] (2004) Directorate of Information Planning and Evaluation Activities of Maternities Lagoon Region 2. Abidjan, 10.

[6] WHO (1998) World Health January-February No. 1.

[7] Cellule de Planificationet de Statistique (CPS/SSDSPF), Institut National de la Statistique (INSTAT/MPATP), INFO-STAT et ICF International (2014) Enquête Démographiqueet de Santé au Mali 2012-2013. CPS, INSTAT, INFO-STAT et ICF International, Rockville.

[8] Labama, L. (1995) Home Birth, a Risk to Mother and Child. Medical Panorama 12: 720-723, Kisangani (DRC).

[9] WHO (2006) World Health Report. WHO, Geneva.

[10] Lankoande, J., Sodo, B., et al. (1996) Maternal Mortality at the Maternity Ward of the Yolgo Ouedraogo National Hospital in Ouagadougou: About 132 Cases Collected in 1995. Document Hospital Archives, Ouagadougou, 74.

[11] Kouakou, A. (1997) Epidemiological Profile of Women Consulting at Yopougon-Attié Maternity Ward after Home Birth. Th. Med., Abidjan, 120. 
[12] Diallo, F.B. (1999) Medical and Socio-Cultural Problems of the Mismatch between Rates of Antenatal and Assisted Births in the 4 Natural Regions of Guinea. Black African Medicine, $46 \mathrm{p}$.

[13] Olsen, O. (1997) Meta-Analysis of the Safety of Home Birth. Birth, 24, 4-13. https://doi.org/10.1111/j.1523-536X.1997.tb00330.x

[14] Chamberlain, G., Wraight, A. and Crowley, P. (1997) Home Births-The Report of the 1994 Confidential Enquiry by the National Birthday Trust Fund. Parthenon Publishing, Nashville.

[15] Wiegers, T.A., Keirse, M.J., Van der Zee, J. and Berghs, G.A. (1996) Outcome of Planned Home and Planned Hospital Births in Low Risk Pregnancies. Prospective Study in Midwifery Practices in the Netherlands. BMJ, 313, 1309-1313. https://doi.org/10.1136/bmj.313.7068.1309

[16] Hutton, E.K., Reitsma, A.H. and Kaufman, K. (2009) Outcomes Associated with Planned Home and Planned Hospital Births in Low-Risk Women Attended by Midwives in Ontario, Canada, 2003-2006: A Retrospective Cohort Study. Birth, 36, 180-189. https://doi.org/10.1111/j.1523-536X.2009.00322.x

[17] Janssen, P.A., Saxell, L., Page, L.A., Klein, M.C., Liston, R.M. and Lee, S.K. (2009) Outcomes of Planned Home Birth with Registered Midwife versus Planned Hospital Birth with Midwife or Physician. CMAJ, 181, 377-383.

https://doi.org/10.1503/cmaj.081869

[18] Falcon, C. and Brillac, T. (2013) Giving Birth at Home or in the Hospital. Comparison of Risks through a Review of the International Literature. Obstetrics and Fertility Gynecology, 41, 388-393.

[19] Lindgren, H.E., Radestad, I.J., Christensson, K. and Hildingsson, I.M. (2008) Outcome of Planned Home Births Compared to Hospital Births in Sweden between 1992 and 2004. A Population-Based Register Study. Acta Obstetricia et Gynecologica Scandinavica, 87, 751-759. https://doi.org/10.1080/00016340802199903

[20] Munier, M. (2011) Global Accompaniment with Home Birth in France from 1997 to 2001 . 


\section{Investigation Sheet}

\section{Identification of the Woman}

No Dossier /

Entry: Date: Time:

Q1. Name and surname: /

Q2. Age (year-to-year))/

Q3. Origin: /

1) Commune V, 2) Common VI, 3) Other Municipality of Bamako (precise), 4) Outside Bamako (precise)

Q4. Ethnie: /

1) Bambara, 2) Malinké, 3) Peulh, 4) Senoufo, 5) Dogon, 6) Sonrhaï, 7) Bobo, 8) Moor, 9) Soninké, 10) Other (specified).

\section{Q5. Marital status:/}
1) Bride
2) Single

Q6. Diet / /

1) Polygamy

2) Monogamy

\section{Q7. Religions: /}

1) Muslim, 2) Christian 3) Animist 4) None

\section{Q8. Profession /}
1) Housewife
2) Saleswoman
3) Hairdresser
4) Teacher
5) Other

Q9. Statementnote: /

1) Educated

2) Uneducated,

Q10. Obstetric history: /
1) Gestity: /
a) Primigeste
b) Paucigeste (2 - 3)
c) Multigeste (4 - 5)
d) Large multigesist (at 6)
2) Parity: /
3) Live child: /
4) Born deaths / /
5) Mort in utero / /
6) Abortion: /
7) Intergenesic interval //
8) Previous assisted birth at home Yes, No / ' 
9) Previous un assisted birth at home: /

5.1. Yes, 5.2. Not

10) If so which of the births: /

11) This child is it:

a) Living

b) Neonatal death

c) Death

12) Was there any complications during this unsured delivery Yes , No / '

Q11. Surgical history: / /

1) Caesarean

3) Cure of prolapse

4) GEU.

5) Ovarian cyst

6) Myomectomie

7) Other: (to be specified)

Q12. Profession of the procreator: /

1) Paying function

2) Non-remunerative function,

Q13.Addressed by:

1) Family, 2) Neighbors, 3) Security authority: //

a) Police, b) Gendarmerie v. Civil Protection,

4) Other (to be specified):

Q14. Reason for admission:

Why did you come to see after giving birth at home?:

\section{Pregnancy History}

\section{Q15. Prenatal consultation /}

1) YES 2) NO

1) Number:

2) Author /

1) Qualified personnel, 3) Unqualified personnel, 4) Unspecified.

3) Location /

1) CSCOM, 2) CS Ref, 3) Hospital, 4) Private structure.

4) Prenatal check-up/1. Yes, two. Not

5) Ultrasound / / 1. Yes,2. Not

- Number: / /

6) If not, why didn't you do the prenatal checkups: 
7) Pregnancy age: /

8) Prophylaxis: MS / Other (specified): / /

9) Iron supplements / / 1. Yes, two. Not

10) Folic acid / / 1. Yes,2. Not

11) VAT1 Yes / / No / / VAT2 Yes/ / No / /

12) Why didn't you do prophylactic care

13) Knowledge of the delivery plan: /- 1. Yes, two. Not

\section{Review at the Entree}

\section{Q16. Physical examination:}

Blood pressure inf. 13/8 cm hg/Sup/equals $14 / 9 \mathrm{~cm} \mathrm{hg/}$

Temperature 'C:37' inf 37 '/ 37-38 / '38'

Maternal pulses in puls/min: inf at 80/, 80 - 99/

Mucous coloration / /

Respiratory frequency / /

Other (to be specified) / /

\section{Q17. Patient Awareness}

1) Good, 2) Obsessed, 3) Coma: Yes / / No / /

Glasgow score / /
a) $1-4$
b) 5 - 7
c) $8-12$

Q18. Accouchement / / Date:

Time (in) /
a) $00 \mathrm{H}-06 \mathrm{H}$
b) $6 \mathrm{AM}-12 \mathrm{PM}$
c) $12 \mathrm{pm}-6 \mathrm{pm}$
d) $6 \mathrm{PM}-00 \mathrm{AM}$

Location / /

1) Along the way, 2) Home, 3) Car, 4) Ambulance

4) Other (to be specified)/ /

Q19. Who will you attend the birth?

Have you paid this person: Yes / No /

Q20. Delivery/Date and Time:

1) Place:

2) Qualified person / / unqualified person / / 

3) spontaneous / / artificial / / Active /
4) Along the way: Yes / / No / /
5) Health structure:

Q21. Section of the cord / Date: Time:
1) Place:
2) Author //
3) Section materials / / a) Sterile b) Not sterile

Q22. Placenta and membranes /
1) Complete
2) Incomplete
3) Not seen

\section{Evolution of the General State of the Mother}

Q23. Simple suites: /- 1) YES, 2) NO

It does not cause:.......

Q24. Hemorrhage of the immediate post partum / 1) Yes, 2) No, no, no

a) Uterine atony: / / 1) YES, 2) NO

b) Placental retention: /1) YES, TWO. NO, NO, NO

If so 1.1 Total 1.2 Partial / /

c) Injury to soft parts

Perineum / 1. Intact

2) Perineal tear:
2.1) $1^{\text {st }}$ degree
2.2) $2^{\text {nd }}$ degree
2.3) $3^{\text {rd }}$ degree

3) Complete tear

Col // 1) Oui 2) Non

Vagina / / 1) Yes 2) No

Other// 1) Vesical, 2) Urtrale, 3) FVV 4) FRV

d) Bleeding Disorder

Q25. Treatment and care

Hospitalization /- 1) Yes, 2) No

If so cause

Q26. Vesical Poll Yes / No /

Q27. Uterine Massage Yes / No /

Q28. Uterus tonic (oxytocin infusion) // 1) Yes 2) No

Q29. Uterine revision: // 1) YES, 2) NO

If so result: 1.1. Regular uterine cavity, 1.2 Continuity solution,

1.3 Bladder injury.

Q30. Suture of lesions / / 1) Yes 2) No

Q31. Anti-antibiotic therapy SAT or VAT: Yes / No /

Q32. Blood Transfusion: 1) YES, 2) NO

Q33. Other treatments: to be specified: / 
Q34. Post-care monitoring / 1) Yes, two. No, no, no

-TA: /____ /
-Safety Globe: / ' ' ' ' ' ' ' ' ' '
-Hemorrhage / / 1.Yes 2.No

Q35. Laparotomy: No/ / Yes / / /

1) Vascular Ligature

2) B lynch (suture compression)

3) Ncho

4) Hysterectomy

5) Other (to be specified):

Q36. Mother's result

1) Living

2) Deceased: / / 1. Yes, two. Not

Location: / / /

Cause:/

Date etHeure

\section{New State Has Arrived}

Q37. Number of nouveau né newborns: /

Q38. Newborn status J1/ J2/N1 -normal, $\mathrm{N} 2$ abnormal

Q39. On the way to the new baby:

a) Breathe or cry: Yes / No /

b) A good muscle tone: Yes / No /

c) Term: Yes / No /

Q40. Weight (in gram) $\mathrm{J} 1 / \mathrm{g}$

$$
\mathrm{J} 2 / \_/ \mathrm{g}
$$

Q41. Size (in centimeters) J1/

$$
\mathrm{J} 2 / \ldots
$$

Q42. Sex J1// 1-M 2 F

$$
\mathrm{J} 2 /
$$

Q43. Resuscitation: / 1) Yes, two. No If so cause: ........

Q44. Malformations / ___ 1) Oui, 2) Non

If so specify

Q45. Other lesions /: 1) Trauma, 2) Fracture, 3) Sero-blood bump, 4) Bruises, 5) No.

Q46. Result of the newborn J1 / J2/

Alive: /

Fresh stillborn: / Death not macerated / Deceased / ' ' background: 
Q47. Referred to 1. Yes, two. No, no, no

Q48. Why did you give birth outside of the maternity ward?

Q49. What does the procreator of childbirth outside of motherhood think?

\section{State of Mother's Knowledge}

Q50. How do you feel after giving birth outside of maternity?

Q51. Are there any benefits, from non-maternity birth to medical delivery?

Q52. What will be the choice of where you will be later? 